\title{
Horizonte epistemológico del término ciencia jovial en Nietzsche. Pre comprensión de la obra a partir del título.
}

\section{Epistemological horizon of the term gay science in Nietzsche. Pre- understanding of the work from the title.}

\author{
González, María Paz \\ Estudiante del Profesorado y la Licenciatura en Filosofía \\ Universidad Nacional del Nordeste \\ peaceandlove969@gmail.com
}

Resumen

El término ciencia jovial utilizado por Nietzsche está íntimamente vinculado a su idea de espíritu libre, pues esta última constituye una condición necesaria para su surgimiento. La liberación de la que habla refiere a un abandono de la tradición científica, filosófica y moral que ha imperado históricamente, conduciendo al hombre a una visión errónea de la vida, influyendo, por medio de engaños, en su manera de conocerla.

Dicho término encierra en si una propuesta gnoseológica novedosa que reconoce al hombre como un ser indefenso, finito, corpóreo y social, lo cual tiene como consecuencia que también sea un ser que conoce, nombra y crea la realidad, lo que da lugar a una multiplicidad de perspectivas.

Palabras clave: jovialidad, conocimiento, liberación, espiritualidad, perspectiva.

\section{Abstract}

The term jovial science used by Nietzsche is intimately linked to his idea of free spirit, since the latter constitutes a necessary condition for its emergence. The liberation of which he speaks refers to an abandonment of the scientific, philosophical 
and moral tradition that has historically prevailed, leading man to a wrong view of life, influencing, by means of deceit, in his way of knowing it.

This term contains in itself a novel gnoseological proposal that recognizes man as a helpless, finite, corporeal and social being, which has as a consequence that it is also a being that knows, names and creates reality, which gives rise to a multiplicity of perspectives.

Keywords: joviality, knowledge, release, spirituality, perspective.

\section{Introducción}

Parece innegable la importancia del título en cualquier obra escrita, ya sea filosófica, literaria, científica o de cualquier otra índole, y esta importancia no se limita a las obras escritas, sino que toda creación humana, por lo general, merece un nombre, un título, que encierra en sí una primera impresión de lo que vendrá, la significación de la obra resumida en unas pocas palabras o, como señala Daniel Dei (2006), lo específico, lo puntual que interesa al autor, la parte primordial dentro del todo es expresada en forma de título.

En relación con esto, la presente monografía, centrada principalmente en la obra de Friedrich Nietzsche "La ciencia jovial", publicada por primera vez en 1882 y luego reeditada en 1887, busca dar cuenta de la relevancia del título de dicha obra para una mejor comprensión o pre comprensión de la misma. Para ello buscará esclarecer la significación del término ciencia jovial, poniendo al descubierto los límites que circunscriben su significado y el contenido que encierran dichos límites, es decir, aquello que, a pesar de no ser dicho, se comprende en él. Estos límites no tienen que ver únicamente con lo que el autor entiende propiamente por ciencia jovial, sino también aquello que, ya sea por alteridad, también forma parte de su significación.

Esto quiere decir que no sólo se va a buscar delimitar el significado directo y específico del término, también se intentará complementar dicho significado con las múltiples críticas y propuestas nietzscheanas relativas al tema del conocimiento, 
puesto que esta clarificación a su vez obedece a otro fin, hallar la relación existente entre el término ciencia jovial y la propuesta gnoseológica del autor. Para lo cual va a ser necesario especificar en qué consiste dicha propuesta en torno a la teoría del conocimiento, señalando las características que se consideren más relevantes para este fin. Teniendo en cuenta que entre la epistemología que se interesa por la ciencia y la gnoseología que problematiza el conocimiento existe una estrecha relación cuyo estudio permitirá clarificar la postura de Nietzsche respecto del conocer.

Para cumplir con lo propuesto, se va a utilizar principalmente la obra antes mencionada, así como también bibliografía complementaria que permita dar cuenta de su autor y del contexto en el cual escribe su obra. Para el desarrollo del segundo objetivo, relacionado con la propuesta gnoseológica del autor, se tomará como marco delimitador dentro del cual moverse los cinco problemas fundamentales del conocimiento mencionados por Johannes Hessen ${ }^{1}$, considerados de gran utilidad para señalar las cuestiones propias de la teoría del conocimiento, lo que permitirá identificar esas cuestiones dentro de la obra que se está trabajando. Finalmente, se expondrán las conclusiones a que se lleguen a partir de lo expuesto en el desarrollo, buscando proporcionar una solución tentativa a los problemas que subyacen a los objetivos propuestos.

\section{Breve análisis sobre Nietzsche y su contexto}

Puesto que Friedrich Nietzsche es un autor célebre, en el ámbito académico sobre todo, pero también fuera de él, no se va a profundizar mucho en dar detalles de su vida. Sólo muy brevemente se va a mencionar que fue, entre otras cosas, un filósofo alemán, nacido en el año 1844 en el municipio de Rocken, y muerto en el año 1900, a los 55 años, en Weimar. Su vida discurre en la Modernidad, período histórico que va a criticar repetidamente en sus escritos.

\footnotetext{
${ }^{1}$ Filósofo alemán que vivió entre los años 1889-1971. Se interesó por la gnoseología, plasmando ese interés en su obra "Teoría del conocimiento" (1992), obra difundida en el ámbito hispánico luego de ser traducida por el filósofo José Gaos.
} 
En el transcurso de su vida escribió múltiples obras, éstas serán ordenadas por los estudiosos dividiéndolas en períodos, los mismos varían en cantidad y en criterios de distinción dependiendo de las pautas de clasificación de quien realice el ordenamiento. En esta oportunidad, el criterio que se va a emplear será el de Garro Sánchez, Julio Martín Toribio ${ }^{2}$, quien sostiene la existencia de cinco periodos en la producción nietzscheana, de los cuales va a interesar especialmente el cuarto período, denominado "del retorno a sí mismo", debido a que en éste ubica a "La ciencia jovial", el texto principal que se va a trabajar.

Dicho período inicia con "La ciencia jovial" y abarca el tiempo transcurrido entre agosto de 1881 hasta febrero de 1885, concluyendo con "Así habló Zaratustra", obra que ubica en este mismo período señalando que la primera forma parte del período "de embarazo" que culminó con la escritura del Zaratustra. Esta etapa se distingue por la nueva temática y experiencias que incluye el autor a su pensamiento, como ser la aparición del "eterno retorno" y el "amor fati", dos conceptos fundamentales del pensamiento de Nietzsche.

Cabe señalar que, si bien comienza la escritura de "La ciencia jovial" en junio de 1881, éste comienza a gestarse en septiembre de 1879 , estrechamente vinculado a "Aurora", libro inmediatamente anterior, pues en un primer momento tenía intención de ser una continuación de dicha obra. Sólo en el transcurso de la escritura adquiere un tono y estilo propios que dan lugar al libro, aún incompleto, publicado en agosto de 1882.

En su introducción, José Jara, señala la importancia del contexto histórico del autor, así como de las circunstancias específicas que lo envolvían en el momento en que escribía La ciencia jovial. A saber, en lo relatado por Karl Jaspers (1963) en su obra "Nietzsche", el período que abarca desde la gestación de la obra hasta su publicación está marcado por un continuo padecimiento por parte de Nietzsche debido a la enfermedad que lo asolaba, recordándole su finitud, y que le había obligado a renunciar a su trabajo como profesor así como a alejarse de los círculos que

\footnotetext{
2 "Los círculos del destino. Eterno retorno y amor fati en Friedrich Nietzsche". (Tesis EAP Filosofía). (2003). Universidad Nacional Mayor de San Marcos, San Marcos, Perú. Recuperado de: http://sisbib.unmsm.edu.pe/bibvirtualdata/Tesis/Human/Garro SJ/enPDF/Cap1.pdf
} 
frecuentaba debido a sus constantes viajes en busca de un clima favorable que aliviara sus padecimientos, lo que le permitió entrar en contacto con todo tipo de viajeros y nuevas experiencias, a la vez que aprovechó esas circunstancias para dedicarse a la lectura. Hacia fines de este período el autor es absorbido por el regocijo debido a una repentina recuperación de la salud, que lo motivó a volver al mundo, a formar parte de él entre los demás hombres, abandonando la soledad que lo había acompañado desde hacía unos años atrás. Este paso por la enfermedad, que lo llevó a una vida nómade y solitaria, y su posterior recuperación de la salud, y con ella el surgimiento de un nuevo anhelo por vivir, de una actitud positiva ante la vida, de afirmación de ésta, se relacionan íntimamente con la producción de su obra, influyendo en ella en gran medida, como podrá constatarse más adelante.

\section{Determinación del término "ciencia jovial" en Nietzsche}

Como ya se mencionó, en este trabajo se busca, primeramente, esclarecer el significado del término ciencia jovial en el pensamiento de Nietzsche. Para ello habrá que remitirse a lo dicho por el autor en el prólogo a la segunda edición, agregado en 1887, de la obra que se va a trabajar, así como también a la introducción de dicha obra, donde el traductor, José Jara, agrega algunas consideraciones relevantes a este fin. Así como también a la obra en su conjunto y algunos aportes tomados de fuentes externas que serán mencionados en su momento.

Debido a la estrecha relación que guarda con el propósito que se persigue, cabe mencionar la importancia que atribuye José Jara al subtítulo agregado por Nietzsche en la segunda edición: "la gaya scienza", subtítulo que deja entre paréntesis y comillas, y que no traduce al alemán pues perdería la significación que buscaba darle, además de no poder desobedecer al sentido histórico, muy presente en su pensamiento, que le impedía apropiarse del pasado provenzal al que hace referencia, esa cultura provenzal, que elogia y agradece pues "le mostraría que él no está sólo ni carece de antecedentes históricos en la actitud y en el estilo que se manifiestan en La ciencia jovial" (Nietzsche, 
1999, p. IX). Por lo tanto, la incorporación del subtítulo contribuye a una mejor comprensión del sentido del título y del estilo que adopta la obra en general.

Volviendo al título de la obra, Nietzsche (1999) va a decir que ciencia jovial "significa las saturnales de un espíritu que ha resistido pacientemente una larga y terrible presión (...) y que ahora de una sola vez es asaltado por la esperanza, por la esperanza de salud, por la embriaguez de la curación" (p. 1). Para entender esto, primero habrá que remontarse a la explicación sobre las saturnales que da José Jara, manifestando que eran fiestas romanas dedicadas al dios Saturno en las cuales los hombres recuperaban, temporalmente, su libertad. En estas fiestas los hombres se liberan de las formas oficiales y legales de la vida pública, que actúan sobre ellos como una enfermedad que los presiona, los somete y los priva de sus fuerzas y riquezas, dando lugar únicamente a un vivir con limitaciones, en carencia y, por lo tanto, a un filosofar desde las carencias.

De esto resulta una filosofía devenida en necesidad, una necesidad inspirada por la enfermedad del cuerpo, que es a su vez una enfermedad cultural, propagada por ésta, que empuja al espíritu a buscar lo plácido, lo suave, aquello que lo libre de su dolor, lo que va a encontrar precisamente en todas aquellas formulaciones filosóficas, éticas, religiosas y estéticas que claman por un más allá trascendente, por un fin último universal de la vida, y por el abandono de las pasiones y del placer, en último término, por un abandono del cuerpo y una actitud negativa ante la vida. En este sentido considera las formulaciones metafísicas como síntomas de un determinado cuerpo, cuya enfermedad es producto de los juicios y valores inculcados históricamente y, a la filosofía en general, como resultado de una mala comprensión del cuerpo en tanto es marginado y relegado de toda importancia.

Esta filosofía enferma, de las carencias, es criticada por Nietzsche, quien ve en la liberación del espíritu la "esperanza de salud" que haría de la filosofía un lujo y no una necesidad, devolviendo al hombre sus fuerzas y riquezas, dando lugar a una nueva forma de filosofar, rica en cambios, que no desprecia a la enfermedad en sí, sino que reconoce el provecho que se puede obtener de ella, en tanto "sólo el gran dolor (...) nos obliga a los filósofos a ascender hasta nuestra última profundidad y a apartar de 
nosotros toda confianza, toda benignidad, encubrimiento, clemencia, medianía, entre las que previamente habíamos asentado tal vez nuestra humanidad" (Nietzsche, 1999, p. 5). Resultando de ello un hombre espiritualizado que ama la vida, a pesar de que desconfía de ella y la problematiza; que conoce un nuevo tipo de felicidad basado en la desconfianza y en la voluntad de preguntar sin reservas.

Podría decirse que este nuevo hombre ha desarrollado lo que Nietzsche llama en el aforismo 2 de La ciencia jovial "conciencia intelectual", la cual se entiende como la intelectualización de la conciencia moral, es decir, un deseo por ser consciente de las razones por las cuales se rige la vida y los juicios de valor en conformidad con tal o cual creencia, se trata de un cuestionarse constantemente sobre la existencia misma y los valores que la ordenan con el fin de crear nuevos instintos que contribuyan en la conservación del sujeto. En el aforismo 25 el autor da a entender que esta conciencia intelectual constituye una condición necesaria para quien se considere un "sujeto predeterminado para el conocimiento", pues la negativa a cuestionar lo impuesto implicaría un acostumbramiento a las leyes, valores y creencias dominantes, haciendo prevalecer las mentiras de "los conservadores de todos los tiempos", término utilizado por el autor para referirse a los autodenominados representantes de la moral y de la religión, a quienes conviene que la conciencia intelectual permanezca ausente en los hombres para conservar su poder y hacer prevalecer las mentiras que han añadido y que, con el paso del tiempo, se han convertido en hábitos.

Esta nueva forma de pensamiento, propuesta por Nietzsche, no admite separación alguna entre cuerpo y alma, sino que reconoce la mutua dependencia entre ambas dimensiones, en tanto no pueden existir por separado. Admitiendo una "unidad del organismo", que da cuenta de la enorme importancia que tiene el cuerpo para el pensamiento en tanto "continuamente tenemos que parir nuestros pensamientos desde nuestro dolor, y compartir maternalmente con ellos todo cuanto hay en nosotros de sangre, corazón, fuego, placer, pasión, tormento, conciencia, destino, fatalidad" (Nietzsche, 1999, p. 4). Dando cuenta así de la recíproca influencia entre estas partes, consideradas como un todo orgánico, que puede apreciarse en la 
filosofía, en tanto arte de transfiguración, que adopta diferentes formas en el pensamiento del hombre en consonancia con las muchas saludes que este transita.

En el aforismo 11, el autor hace referencia a esta cuestión cuando menciona el típico error de muchos hombres y culturas de considerar a la conciencia como el núcleo de lo humano, como lo más propio de él, en detrimento de la dimensión corpórea del hombre; cuando en realidad, esa claridad sobre sí mismo es lo último que se ha desarrollado en él, es decir lo menos acabado y por lo tanto más débil.

Señala que este error, por sí sólo, habría dado fin a la especie humana y que, de no ser por la fuerte asociación que existe entre los instintos conservadores, habría sido inevitable que sucumba dicha especie. Haciendo ver de este modo que la sobreestimación de la conciencia, que se reprodujo históricamente y aun hoy se sigue sosteniendo, ha dado lugar a una proliferación de errores que se han hecho cuerpo y que, la única manera de impedir que se sigan propagando será a partir del reconocimiento de que hasta ahora solo los errores, resultantes del desconocimiento de la conciencia como órgano derivado y débil, se han hecho cuerpo e instinto. Tarea que, para ser llevada a cabo, amerita del reconocimiento de que la claridad sobre sí mismo, también llamada conciencia, se funda y se remite a errores. Lo que va a dar lugar a una verdadera búsqueda de claridad sobre sí y al posterior desarrollo de la consciencia, cuyo crecimiento ha sido impedido por su sobreestimación; así como también a un nuevo saber, más acorde a las nuevas exigencias nietzscheanas, que será corporeizado y hecho instinto.

Teniendo en cuenta lo expuesto hasta el momento puede pensarse que el término ciencia jovial en Nietzsche hace referencia a una liberación del espíritu, a un despertar que permitiría rechazar la influencia inconsciente que ejercen las enfermedades sobre el espíritu, dando lugar a una ciencia que no pretende ocupar el lugar de Dios, es decir que no busca dar las respuestas a todo, que no busca ser la instauradora de la verdad ni proclama por un fin último universal de la existencia, sino que pretende actuar desde la incertidumbre, de manera ingenua pero osada, experimentando permanentemente, pues considera que la teoría pura, sin una dimensión práctica, es una pulsión de muerte, en tanto se estanca en el goce del 
pensamiento y la especulación sin ir más allá, sin salir al mundo concreto y efectivo que lo rodea y del cual forma parte, en la medida que es también un cuerpo.

En concordancia con esto puede decirse que la filosofía necesita de la ciencia jovial en tanto ésta le permitiría salir de esa pura teorización que busca respuestas en lo trascendente, negando la existencia concreta y con ello la vida.

Para terminar con esta clarificación resulta interesante dejar en claro que la ciencia jovial propuesta por Nietzsche se distingue en muchos aspectos de la ciencia moderna, que es la concepción de ciencia más habitual. Una de las distinciones más evidentes es que no busca formular leyes, pues renuncia a las certezas indubitables de la ciencia moderna, renuncia a la búsqueda de la verdad, proponiendo en su lugar la idea de que todo saber se funda en acuerdos comúnmente aceptados por una comunidad determinada para poder sentar ciertas bases comunes que permitan la vida en convivencia a partir de cosmovisiones compartidas. Es decir que, en realidad, no es posible conocer el mundo circundante tal cual es, sólo se lo conoce en perspectiva de forma desfigurada.

Esto da cuenta de otra diferencia, la ciencia jovial renuncia a toda pretensión de objetividad, no busca "apartarse" del mundo para conocerlo, sino que reconoce la imposibilidad de esta pretensión en la medida que es el hombre quien crea el mundo cognoscible, quien lo moldea a la vez que se moldea a sí mismo. A partir de esto podría considerarse que, antes bien que una renuncia de la "objetividad", lo que hace Nietzsche es reconceptualizar este término, redefinirlo desde una mirada perspectivista, sosteniendo que lo "objetivo" va a ser aquello que se conozca a partir de un mayor número de miradas, es decir de perspectivas e interpretaciones.

Si bien las diferencias continúan, este apartado quedaría incompleto si no se señala alguna coincidencia entre las dos formas de ciencia. A este fin cabe mencionar el fuerte interés de ambas en el mundo sensible; interés que distingue a la ciencia jovial de un sin número de escuelas filosóficas que rechazan, por vulgar y superfluo, todo saber atado a lo empírico. En cambio, la ciencia jovial, al igual que la ciencia moderna reconocen como fundamento de todo saber a la existencia concreta y sensible, y al cuerpo como una parte fundamental de ese saber, en la medida que es el 
modelo a partir del cual el hombre pensante desarrolla su pensamiento, pues la naturaleza del cuerpo "consiste en trascenderse, en ir-más-allá-de-sí, en superarse en el "espíritu»" (Silva, 2011, p. 400). Es decir que sin un cuerpo al cual trascender para entrar en contacto con el mundo externo no habría conocimiento posible.

\section{Concepción gnoseológica de Nietzsche}

A partir de lo dicho puede afirmarse la existencia de una propuesta gnoseológica en la obra de Nietzsche, un interés por cuestiones referidas al conocimiento, a su posibilidad, su origen, su validación, alcances y limitaciones entre otras cosas. Pero ese interés, en Nietzsche, no se limita al plano puramente gnoseológico, sino que abarca un espectro más amplio que incluye cuestiones vinculadas a la espiritualidad de uno y la relación de ésta con la corporeidad. Como vimos anteriormente, ambos planos para el autor son indisolubles y cualquier compresión de la realidad que se detenga en uno de ellos desconociendo al otro va a estar necesariamente incompleto. Podría sostenerse que en esto reside lo novedoso de su propuesta, en la unificación conceptual de estos dos planos que, por lo general, son estudiados de manera escindida.

Pero antes de comenzar con el abordaje de la propuesta gnoseológica nietzscheana parece necesario clarificar la noción de gnoseología que se está trabajando en la presente monografía, para así distinguirla de la noción de epistemología. Dos conceptos problemáticos al momento de fijar límites entre ambos, tarea que ha resultado dificultosa debido al parecido con que son utilizados, lo que ocasionó confusiones y trabas para su comprensión, revelando la necesidad de definirlos antes de cualquier abordaje del tema. Para ello se va a utilizar, principalmente, los aportes al respecto hechos por Fidel Martínez Álvarez, Eloy Ortiz Hernández y Ania González Mora (2007) en su artículo “Hacia una Epistemología de la Transdisciplinariedad" publicado en la revista Humanidades Médicas.

Dicho esto, se va a sostener que cuando se hable de gnoseología se estará haciendo referencia a una disciplina cuyo principal interés es el conocimiento, esto 
queda suficientemente evidenciado si se tiene en cuenta que también se la conoce como "teoría del conocimiento", si bien este mismo nombre suele ser utilizado por algunos autores, como ser Johannes Hessen, para hacer referencia a la epistemología, en este caso se lo va a entender exclusivamente como sinónimo de gnoseología, en tanto su interés por el conocimiento es más general, es decir que no se detiene en un tipo de conocimiento en particular, sino que tiene en cuenta las diversas formas que este puede adoptar y las múltiples problemáticas que esa diversidad trae consigo.

En cambio, al hablar de epistemología se estará aludiendo a aquella disciplina que se interesa por un determinado tipo de conocimiento, desconociendo o desinteresándose por las demás formas que este puede adquirir. Su objeto específico es el conocimiento estrictamente científico y todas las cuestiones que lo atraviesan. Es menester dar cuenta de que la mención de esta disciplina en el título del presente trabajo no es errónea, sino que hace referencia al principal objetivo que persigue, es decir delimitar los alcances del término "ciencia jovial" en Nietzsche, para luego poder realizar un abordaje gnoseológico en relación al mismo.

Hecha esta distinción se puede pasar a la justificación de la afirmación que se hizo al principio de este apartado sobre la existencia y presencia de una gnoseología nietzscheana. Para ello se va a utilizar como guía orientadora los cinco problemas en torno a la teoría del conocimiento propuestos por Johannes Hessen (1992) en su obra "Teoría del conocimiento". Dichos problemas son los siguientes: la posibilidad del conocimiento, el origen del conocimiento, la esencia del conocimiento, las especies de conocimiento y el criterio de verdad. No se tendrán en cuenta las soluciones dadas por el autor a cada una de estas problemáticas, sino que van a funcionar como guías que orienten la indagación de este trabajo en la búsqueda de posibles respuestas por parte de Nietzsche en su obra "La ciencia jovial". En la medida que se encuentren en la obra mencionada respuestas hechas de forma indirecta a todos o uno de estos problemas, se va a considerar que la afirmación antes hecha está justificada y ha sido validada.

Comenzando por la cuestión del origen del conocimiento, se puede hacer mención del aforismo 355 que explícitamente refiere a este tema, si bien el título del mismo es "el origen de nuestro concepto "conocimiento»", en él se puede vislumbrar 
una pregunta que remite a una afirmación antes hecha en el aforismo 354; la pregunta es “¿no será el instinto del temor el que nos manda a conocer?" (Nietzsche, 1999, p. 220). Esto permite formular una respuesta tentativa para la cuestión del origen del conocimiento, sosteniendo que es el temor, aquel sentimiento básico del hombre, el que da lugar a la menesterosidad del conocer.

Ese temor se funda en la marcada indefensión del hombre frente al mundo que se presenta fundamentalmente como hostil y peligroso, haciendo de la especie humana el animal con mayor vulnerabilidad al carecer de garras, dientes afilados o cualquier otro atributo fisiológico que le pudiera servir para defenderse de los peligros que lo acechan. Por esta razón va a requerir del auxilio de sus semejantes, es decir de los demás hombres del rebaño. Para poder solicitar la ayuda de éstos va a necesitar, primero, la conciencia o mejor dicho el ser-consciente-de-sí-mismo, pues es menester que sepa qué es lo que siente, anhela, necesita, etc. para poder comunicárselo a los demás. Para conseguir esto, es decir la comunicación, va a requerir del lenguaje, de aquella capacidad propiamente humana que permite traducir los datos de la conciencia en símbolos comunicables, y cuyo surgimiento, considera Nietzsche, está íntimamente relacionado al de la consciencia. Pero, lo que principalmente interesa en este apartado no es el origen de la consciencia o el lenguaje, sino del conocimiento. Lo que remite a algo ya dicho, que para comunicar lo que le es menester al hombre antes debe saber qué es lo que necesita, por lo tanto, aquí es donde puede suponerse el origen de la necesidad de conocer, como algo intermedio entre el ser-consciente-de-símismo y el lenguaje, como un paso exigido entre ambos, pues no sería posible comunicar lo que se ignora de sí mismo.

Si bien lo dicho permite formularse una idea del origen del conocimiento, esta respuesta no es lo suficientemente satisfactoria, pues el origen de la necesidad de conocer no es lo mismo que el origen del conocimiento. Aun así, algo a destacar en este punto es el novedoso aporte de Nietzsche al considerar el temor como la fuente de la cual y por la cual surgen aquellas características tan humanas.

Volviendo al tema que compete a este apartado, puede considerarse que el conocimiento no tiene un origen único, pues a pesar de que podría sostenerse que el 
conocimiento-de-sí es puramente racional, se sabe que el surgimiento de la necesidad de conocerse a sí mismo, al igual que el surgimiento de la consciencia y del lenguaje sólo es posible en un ambiente comunitario, es decir que ineludiblemente existe un factor externo y social actuando e interviniendo en ese saber-de-sí. Por lo tanto, puede identificarse en el origen del conocimiento un factor individual, social y empírico a la vez.

Esto nos remite al problema de la posibilidad de conocer. En general, Nietzsche no niega que haya un conocimiento, lo que sí cuestiona son los alcances del mismo. Es decir, reconoce que hay un saber de sí mismo, necesario para la subsistencia, que actúa en él y es comunicable, pero reconoce que ese saber es ínfimo en relación con lo que se ignora de sí, con aquello que permanece fuera de la consciencia. Lo mismo sucede con el conocimiento de las ciencias naturales, sostiene que el gran problema al que se enfrentan estas disciplinas, problema compartido también en parte por la filosofía, es que se asume que lo consabido, es decir lo más conocido, es lo habitual, lo cotidiano, cuando en realidad justamente lo que más se da por conocido es lo que más se desconoce, pues el hábito impide poner como problema, como algo extraño, aquello que se asume consabido.

Por lo tanto, reconoce al hábito, a la cercanía, como un impedimento para el conocer, al igual que la conciencia que, en tanto es producto del instinto de rebaño del hombre, de su necesidad de vivir en comunidad, sólo permite la comprensión de aquellos datos que son comunes y útiles al rebaño, lo no-individual. Haciendo del mundo factible de ser conocido un "mundo de superficies y de signos, un mundo generalizado y hecho común" (Nietzsche, 1999, p. 219) que, por llegar a ser consciente sufre una gran y fundamental corrupción, es decir que lo que podemos conocer del mundo no son más que falsificaciones adaptadas a nuestras necesidades, cuyo principal fin es procurar a la especie humana de aquella tranquilidad propia de quien cree conocer.

En este punto conviene hablar del perspectivismo nietzscheano, para tener una mejor comprensión de a qué se refiere la corrupción cognoscitiva de la realidad. Para ello se hará mención del aforismo 374, en donde el autor da cuenta de la nueva 
infinitud del mundo, que da lugar a las infinitas perspectivas e interpretaciones que se pueden conceder en el proceso de conocimiento de la realidad concreta. José Jara va a sostener que esta infinitud es una consecuencia directa de la proposición nietzscheana que predice la muerte de Dios, pues al no haber un Dios fuente de toda sabiduría, no es posible para la especie humana sostener un discurso de verdad absoluta, dejando abierto el paso al "reino ilimitado de los límites de la finitud humana, que habrá de ser transitado ahora desde el carácter perspectivístico y conflictivo de las interpretaciones" (Nietzsche, 1999, p. 295).

Ineludiblemente, esto último dirige a la cuestión de la validez del conocimiento, pues como ya se dijo anteriormente, no niega que haya un conocimiento, sino que duda de la veracidad del mismo. En el aforismo 354 va a decir explícitamente que "no tenemos, en efecto, ningún órgano para conocer, para la "verdad»" (Nietzsche, 1999, p. 219), es decir que no hay nada que asegure y demuestre que un conocimiento sea verdadero, sólo se puede creer o imaginar que se conoce pero este saber va a estar determinado por las necesidades del rebaño, es decir por lo que sea útil a este, y sólo en tanto útil se lo va a reconocer como conocimiento verdadero. Por lo cual, las perspectivas e interpretaciones aceptadas en un determinado lugar van a depender exclusivamente de la comunidad y sus necesidades y deseos inmediatos; ya no de una fuerza externa considerada omnisciente que proclame qué es lo verdadero. De lo cual resulta que, para Nietzsche, no es posible ningún conocimiento verdadero, ninguna afirmación indudable y universal.

Por esta razón Nietzsche va a sostener que quienes eligen la vida contemplativa, aquellos hombres pensantes que se esfuerzan por comprender la realidad, son los auténticos poetas de la vida en tanto no se limitan a observarla, pues les es propia la fuerza creadora de que carecen los hombres de acción, que los faculta como los primeros creadores del mundo. Puesto que, a partir de sus apreciaciones, perspectivas, escalas, afirmaciones y negaciones, traducidas en forma de metáforas, inventan el mundo cuando pretenden conocerlo por medio del nombramiento de las cosas. Estos nombres posteriormente serán tomados y reproducidos por los llamados "hombres prácticos" y convertido en cotidianeidad, en conocimiento acerca del 
mundo. Se harán cuerpo pasando de ser meros nombres para convertirse en las cosas mismas. Esas metáforas se van a encarnar en las cosas convirtiéndose en sus propios cuerpos en la medida que se las siga afirmando y reproduciendo generación tras generación, hasta que en un momento se habrá olvidado que comenzó siendo una simple metáfora sobre la realidad, para convertirse en la realidad misma, y en la cosmovisión compartida de una comunidad.

Hasta ahora, teniendo en cuenta lo expuesto, pueden identificarse como formas de conocimiento el saber de sí mismo, propio de la consciencia, el conocimiento de las ciencias naturales, cuya inalcanzable pretensión de objetividad pone en duda su validez, y el conocimiento de los hombres contemplativos, que crean el mundo a partir de las metáforas con que lo nombran. Estas formas de conocimiento tienen en común que existen por y para la vida en comunidad, pues son necesarios para la convivencia y la comunicación, para que haya acuerdos en las formas de vida del rebaño. También coinciden en que ninguno de ellos dispone de criterios de validación que ponga su saber fuera de toda duda, pues son verdaderos en la medida que son útiles y no por sí mismos.

Por lo tanto, partiendo de todo lo expuesto, se puede considerar que la esencia del conocimiento es, principalmente, la voluntad de vivir, que actúa en el hombre por medio de la certeza de que para la supervivencia de la especie humana es necesaria la convivencia de los hombres y la ayuda mutua, en tanto animal indefenso que no puede valerse por sí mismo. Esta pulsión de vida es la que influye activamente en la especie humana dando lugar al desarrollo de aquellas características que le son propias y que le permiten subsistir siempre y cuando se encuentre dentro de una comunidad de semejantes, es decir, siempre y cuando acepte su instinto de rebaño. Actualmente esta condición no es indispensable, pues el hombre como especie ya no se encuentra en peligro de desaparecer, en parte por los avances en las ciencias naturales y en las tecnologías, ya no se encuentra bajo el yugo incierto del mundo que lo rodea. Lo que da lugar a nuevas formas de relacionarse entre los hombres y de expresarse la voluntad de vivir. 


\section{Relación entre ciencia jovial y la propuesta gnoseológica nietzscheana}

Una vez que se ha determinado cada uno de estos puntos, es decir, clarificado el término ciencia jovial y definido la concepción gnoseológica presente en la obra de Nietzsche, queda únicamente dar cuenta de la relación existente entre ambas partes, pues teniendo en cuenta que las dos se refieren a la capacidad cognoscitiva del hombre es indudable la presencia de dicha relación.

Buscando dar cuenta de esto, se va a sostener que la ciencia jovial, en tanto término que hace referencia a un tipo de conocimiento en particular, encierra en sí la propuesta en torno a la teoría del conocimiento que el autor presenta en su obra y que se ha caracterizado anteriormente. Puesto que la jovialidad que Nietzsche aspira a introducir en la concepción de ciencia no es más que la proposición de un cambio de paradigma en el habitual proceso cognoscitivo humano. La búsqueda de una nueva forma de conocer y de hacer ciencia por fuera de los límites tradicionales de la ciencia moderna y la filosofía. Sin hacer distinción de estas formas de conocimiento en la medida que ambas están transitando caminos erróneos en su pretensión de hallar la verdad o de conocer la realidad.

Incluso, puede sostenerse que en la ciencia jovial se incluyen conjuntamente la ciencia y la filosofía, quedando en desuso la distinción hecha anteriormente entre gnoseología y epistemología, pues la diferenciación entre conocimiento y conocimiento científico ya no será necesaria, en la medida que se reconozca las limitaciones que impone la ciencia a su saber y se las rechace considerándolas irrealizables. Algunas de estas limitaciones ya se han desarrollado con anterioridad como ser la pretensión de objetividad y la búsqueda de conocimientos verdaderos universalmente, pero también puede nombrarse la imposición de un único método para llegar a ese conocimiento y la distinción que sostienen entre conocimiento científico, considerado el único verdadero, frente a todas las demás formas de conocimiento.

Algo similar sucede con la filosofía, pues la jovialidad de la ciencia implica necesariamente un abandono de muchos de los supuestos filosóficos sostenidos 
históricamente. La propuesta nietzscheana contiene en sí un rechazo fundamental de toda postura que busque respuestas en la trascendencia, en un más allá alejado de todo lo concreto, sin tener en cuenta, o sin darle la importancia que merece, al hecho de que el hombre es un ser corpóreo y social "arrojado" en un mundo material, inmanente; y que esto influye en mayor o menor medida en su proceso cognoscitivo.

Por lo tanto, puede afirmarse que la relación que guardan es tan íntima que no es fácil demarcar los límites entre uno y otro, pues la teoría del conocimiento propuesta por Nietzsche está presente en su concepción de ciencia jovial, y a su vez la ciencia jovial propone un nuevo paradigma para acercarnos a la realidad e intentar conocerla.

Para clarificar más la cuestión resulta interesante tener en cuenta lo expuesto por Sergio Santiago Romero (2017) en su artículo "Arte para ser dichoso. La jovialidad científica de Baltasar Gracián y su relación con Nietzsche", en el que trata acerca de la influencia que el autor español tiene sobre el pensamiento del protagonista de este escrito. Dado que no corresponde al fin de esta monografía, no se intentará dilucidar las dimensiones de dicha influencia, ni entrar en la disputa de si la misma existe o no; lo que interesa del artículo de Romero será el paralelismo que presenta entre la idea de espíritu libre de Nietzsche y la propuesta graciana de Héroe. Respecto a esto, va a sostener que la jovialidad propuesta por Nietzsche, en tanto remite indefectiblemente a la idea de espíritu libre, encierra cierta similitud con la propuesta graciana de Héroe, puesto que ambas defienden una particular forma de existir y conocer, al que Romero va a considerar como "el arte de vivir, es decir, el arte de comprender la vida como es, sin engañarse", sin caer en especulaciones transcendentes, en falsas esperanzas de un más allá independiente de la realidad concreta. Se trata de un desengaño fundamental, de un desenmascaramiento de los ideales que evoca satisfacción y serenidad, y permite conocer y aceptar la vida tal cual es y a partir de ello buscar la mejor manera de salir airoso.

Es un conocer práctico para la vida que no se deja detener por falsos valores ni por absurdas limitaciones convencionales, y que rechaza toda respuesta que se sustente en esperanzas trascendentes. También es un conocer creador, pues en la 
medida que conoce la realidad y la nombra, la va creando, dando lugar a la multiplicidad de perspectivas que confluyen en una misma realidad concreta imponiéndose unas sobre

otras.

\section{Conclusión}

Para cerrar la presente monografía se hace necesario dar cuenta de los principales puntos a que se han llegado, notificar si se han cumplido los objetivos propuestos, es decir, si se ha clarificado el término ciencia jovial, y si quedó suficientemente claro de qué trata la gnoseología nietzscheana. Para finalmente dar cuenta de las respuestas que se han formulado a los problemas subyacentes a cada uno de esos objetivos.

Con respecto a la clarificación del término ciencia jovial en Nietzsche, puede sostenerse que se ha conseguido formular una idea de su significación. La misma está íntimamente vinculada con la liberación del espíritu del hombre. Esa liberación implica una puesta en duda de todo aquello que se presenta como lo único verdadero, correcto, real, como "lo bueno", de todo aquello que es impuesto desde el nacimiento, y que es transmitido generación tras generación como las únicas respuestas posibles ante el misterio que es la vida y la realidad, es decir, los criterios con que se valoran las acciones y los conocimientos. También implica un abandono de todas estas certezas impuestas, que actúan como reguladoras de las formas de sentir, de vivir, de actuar y de pensar y que, históricamente han enfermado al espíritu del hombre con sus formulaciones trascendentes y erróneas. Para dar lugar a nuevas formas inspiradas en la tensión existente dentro de un espíritu liberado que se sabe creador y finito.

Ahora, en relación a la propuesta gnoseológica nietzscheana, ha quedado suficientemente claro que la misma está efectivamente presente en La ciencia jovial. También se ha delimitado algunas de sus características y aportes más significativos. Señalando, entre otras cosas, que el conocer surge como una necesidad, ante la menesterosidad de poder comunicarse con la comunidad, que es necesaria para la supervivencia pero que, por sí sola llevaría al hombre a su fin. También se afirmó que 
es posible conocer, pero que este conocimiento va a estar siempre incompleto, deformado, corrupto, pues lo que se conoce no es la realidad sino la percepción que se tiene de ella en relación con su utilidad social y la perspectiva individual de cada sujeto. En relación a esto, se hizo mención de un tipo de hombres que, mientras pretenden contemplar la realidad para conocerla, en verdad lo que hacen es crearla, pues solo se conoce en la medida que se crea. Finalmente, otro punto que parece importante mencionar es que se ha llegado a la conclusión de que, en Nietzsche, no existe un criterio de verdad, esta no existe o, si existiese, no está al alcance del hombre. Entonces, aquello que se considera "verdadero" no son más que convenciones sociales que han perdurado tanto tiempo que se ha olvidado que lo son. Ahora, sólo queda poner en evidencia la relación que lo une al término antes clarificado.

Con respecto a esto, se va a sostener que el término ciencia jovial encierra en sí, entre otras cosas, la propuesta gnoseológica de que se ha hablado. Puesto que, la liberación del espíritu, el abandono de los cánones valorativos y de las imposiciones que enferman dan lugar a la posibilidad de la duda, de la no-certeza, característica del conocer nietzscheano, en tanto reconoce que aquello considerado conocimiento no es más que un acuerdo, algo que se ha fijado en tiempos remotos y que perdura en la medida que siga siendo útil para la vida del rebaño. Lo cual remite nuevamente al espíritu de la ciencia jovial, en tanto propone poner en duda estos saberes sostenidos a lo largo del tiempo sin ser cuestionados, para dar lugar a nuevas respuestas posibles, a nuevas creaciones. Pues se reconoce que el hombre en tanto nombra las cosas, las crea y, por lo tanto, también puede destruirlas.

Esto da lugar a preguntarse ¿̇la ciencia jovial puede ser considerada una ciencia cuando no busca la verdad, ni siquiera certezas? Con todo esto ¿estaba describiendo el contexto en que vivía o tan lúcidamente pudo prever lo que acontecía en el futuro? Pues resulta difícil leer estas propuestas en relación al conocimiento sin que remitan a los tiempos actuales posmodernos donde prevalece el perspectivismo y el constante enfrentamiento de opiniones a que este da lugar. Asimismo, la renuncia a la búsqueda de la verdad ha pasado a ser algo corriente para muchos, lo que puede verse en la 
multiplicidad de opiniones frente a un mismo tema, opiniones que, en los mejores casos son reconocidas a pesar de las diferencias, pero que llevan a preguntarse ¿en qué medida estas "diferencias de perspectivas" no actúan como una respuesta universal para dar cuenta de que no hay respuesta posible? ¿de qué modo esto afecta a nuestro vivir cotidiano, a nuestro actuar? 


\section{Referencias bibliográficas}

- DEI, D. (2006). La tesis. Cómo orientarse en su elaboración. Buenos Aires, Argentina. Prometeo.

- DÍAZ, E. (2017). Problemas filosóficos. Goya, Argentina. Arandú - Biblos.

- GARRo SÁNCheZ, J. M. T. (2003). Los círculos del destino. "Eterno retorno" y "amor fati" en Friedrich Nietzsche. (Tesis EAP Filosofía). Universidad Nacional Mayor de San Marcos, San Marcos, Perú. Recuperado de: http://sisbib.unmsm.edu.pe/bibvirtualdata/Tesis/Human/Garro SJ/enPDF/Cap 1.pdf

- HESSEN, J. (1992). Teoría del conocimiento. Bogotá, Colombia. Panamericana.

- JASPERS, K. (1963). Nietzsche. Trad. Emilio Estiu. Buenos Aires, Argentina. Panamericana.

- MARTínez ÁlVAREZ, f. ORTiz heRnÁNDEZ, E. \& GONZÁlez MORA, A. (2007). Hacia una epistemología de la transdisciplinariedad. Humanidades Médicas, v.7 no.2. Recuperado de:

http://scielo.sld.cu/scielo.php?script=sci arttext\&pid=S1727$\underline{81202007000200008 \& \operatorname{lng}=e s \& t \mid n g=e s}$.

- NIETZSCHE, F. (1999). La ciencia jovial. La gaya scienza. Trad. José Jara. Caracas, Venezuela. Monte Ávila.

- ROMERO, S. (2017). Arte para ser dichoso. La jovialidad científica de Baltasar Gracián y su relación con Nietzsche. Logos, La Serena, v.27, no.2. Universidad Complutense de Madrid, España. Recuperado de: https://scielo.conicyt.cl/scielo.php?pid=S0719-

$\underline{32622017000200302 \& \text { script }=\text { sci arttext }}$

- SILVA, T. (2011). Rodríguez, Mariano: La teoría nietzscheana del conocimiento. Logos, anales del seminario de Metafísica, v.44. Universidad Complutense de Madrid. Madrid, España. Recuperado de: https://revistas.ucm.es/index.php/ASEM/article/viewFile/37812/36590. 